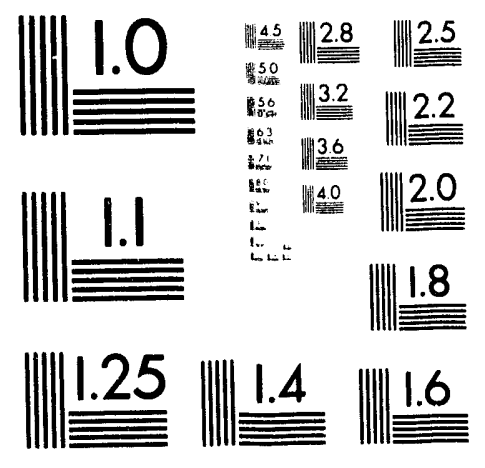





$$
\begin{aligned}
& \text { ARK/ES/CP-7G23.3 }
\end{aligned}
$$

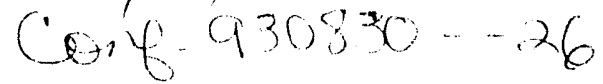

\title{
Performance Comparisons of Enhanced Tubes with Discrete and Wavy Disruption Shapes*
}

\author{
B. Arman and T.J. Rabas \\ Energy System Division \\ Argonne National Laboratory \\ Argonne, IL 60439

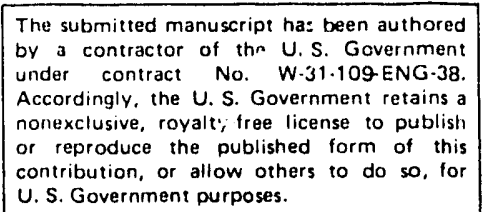

\section{ABSTRACT}

This paper presents comparisons of the friction factors and heattransfer coefficients obtained with enhanced tubes with transverse discrete and almost transverse wavy two-dimensional disruptions. Both experimental data and numerical predictions were used for the comparisons. For the latter a two-layer turbulence model incorporated in a body-fitted, finite-volume method was used.

The disruption shape, discrete or wavy, depends on the manufacturing process. If an extrusion process is used, discrete disruptions (ribs) of various profiles are obtained that are separated from each other by a flat or unaltered inside diameter. If a spirally indenting process is used, a wavy profile is obtained with a continuously varying inside diameter between two adjacent disruption peaks. These disruptions are transverse or almost transverse to the lube axis and separated by a distance that exceeds the reattachment length.

Based on these comparisons, the following conclusions are obtained: (1) the disruption shape is not an important correlating parameter for discrete disruptions, (2) only the friction factor is influenced by the shape for wavy disruptions, and (3) there are major differences between both the friction-factor and heat-transfer performance of discrete and wavy disruptions with the same maximum disruption height and spacing. However, the mos important finding is that the groove radius of spirally indented tubes should be increased becallse of the substantial reduction of the friction factor but only a small decrease in the thermal performance. Additional comparisons of predicted results were made to obtain a fundamental understanding of the influence of these different shapes.

\section{NOMENCLATURE.}

D maximum inside tube diameter

$\mathrm{e}_{\max }$ maximum disruption height

$<e>$ mean disruption height defined by Equation 1

$\mathrm{e}(\mathrm{x}) \quad$ locil disruption height

$f$ friction factor, $f=\Delta p /\left(0.5 p U^{2}\right)$

* Work supported by the U.S. Departmient of Energy, Assistant Secretary for Conservation and Rencwable Encrigy, Office of Industrial Technologics, Office of Industrial Processes, Advanced Industrial Concepts Division, under contract W. $31-1(x)$-Eng-38. h heat transfer coefficient

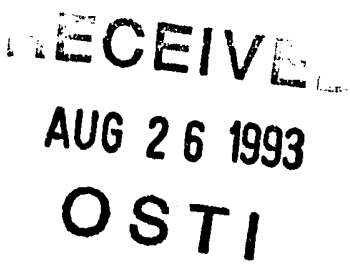

$k$ thermal conductivity

$\mathrm{Nu} \quad$ Nusselt number, $\mathrm{Nu}=\mathrm{hD} / k$

$\mathrm{p}$ pressure

$p \quad$ pitch

Pr Prandtl number

$r_{1} \quad$ groove radius

circular sector radius, Equations $\mathrm{A} 1$ and $\mathrm{A} 2$

$\mathrm{R}$ maximum tube radius

$\mathrm{Re} \quad$ Reynolds number

$\mathrm{U}$ mean velocity

$x$ axial distance

w disruption width

\section{Greek Letters}

$\alpha \quad$ helix angle

$\beta \quad$ contact angle of circular sector, Equation A 1

$\rho$ density

$\tau_{w} \quad$ local wall-shear stress

\section{Subscripts}

$\mathrm{p}$ smooth tube

\section{INTRODUCTION}

The turbule':s, forced-convective heat-transfer performance cian be increased $t y$ a factor of two to three with disruptions of various shapes on the inside surfaces of heat-exchanger tubes. A commonly used geometry consists of disruptions that are transverse or nearly transverse to the tube axis and with a spacing equal to or greater thin the reattachment length. This geometry is one of the most used for single-phase forced-convection applications such as power-plant condensers in the U.S. (Rabas et al., 1990), the U.K. (Rowe, 1983), and the former Soviet Union (Katsman and Kishinevsky, 1983; Nikolaev et al., 1982; Anisimovia et al., 1982). This tube type is also used for feedwater-heater trains of desalination plants (loule and Buhrig, 1973; Inoue et al, 1975). The enhancement mechanism characterized by these geometry constraints is called separation and reattachment (Rabas, 1989).

The disruption shape of these enhanced tube. is dependent on the manufacturing process. If a spirally indenting process is used, il wavy disruption profile is obtained with a continuously varying inside diameter between two adjacent disruption peaks. The wavy profiles

\section{Masith}


depend on the shape of the roller, the tube material, and the tube wall thickness. If an ex:rusion process is used, discrete disruptions (ribs) of various profiles are obtained that are separated from each other by a flat or unaltered inside diameter. Figures $1 \mathrm{a}$ and $\mathrm{lb}$ show typical spirally indented and extruded tubes. The spirally indersed tubes are the most used for the above mentioned applications although tubes with discrete disruptions are widely used in the refrigeration industry.
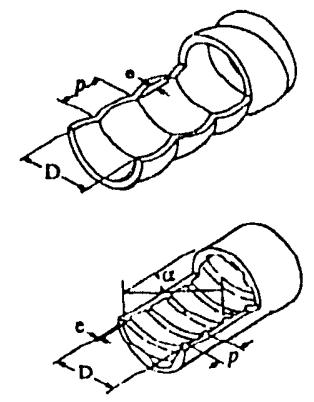

(b)

\section{Figure 1 a) Spirally Indented Tube; b) Extruded Tube}

The tube-geometry parameters that govern the thermal-hydraulic performance of these tubes with the separation and reattachment mechanism are the disruption maximum height, $\mathrm{e}_{\max }$, pitch, $p$, and shape (see Figure 1). However, the major focus of previous investigations was to determine the effect of the disruption height and spacing and to neglect the effect of the shape. As a result, there are many prediction methods that adequately account for these two parameters provided that the tubes used to generate the data base were made by the same manufacturing process and have essentially the same disruption shape.

The next section of this paper will present a review of the literature that addresses the effect of the shape on the thermalhydratulic performance of tubes with discrete and wavy disruption shapes.

\section{PERFORMANCE COMPARISONS}

The effect of the shape on the performance of tubes with the separation and reattachment mechanism has not been extensively investigated. However, there is sufficient data and information to reach some major conclusions. Comparisons of the existing performance data will be presented for tubes with different discrete shapes, different wavy shapes, and discrete and wavy shapes with the same maximum disruption height and pitch.

\section{Discrele Shaves}

Only the two investigations of Nunner (1956) and Hijikata and Mori (1987) made comparisons of experimental data for different discrete disruption shapes of enhanced tubes: rectangular, arc, and sine shapes of the discrete type. The general trend is that both the friction-factor and heat-transfer values decrease as the curvature of the disruption increases; however, the heat-transfer reduction is less than that of the friction factor. Hijikata and Mori (1987) showed that differences in the local heat-transfer measurements existed in the downstream recirculation regions but not in the boundary-layer development regions after the reattachment. It is apparent that the influence of the shape on the heat-transfer and friction-factor values decrease as the pitch increases or as the ribs are moved further apart.

Of the numerous empirical prediction methods, only one (Ravigururajan and Bergles, 1985) was discovered that considers the effect of discrete disruption shapes - rectangular, triangular, and circular (wire inserts). This shape correction was included in the friction-factor correlation but the mean heat-transfer coefficient was assumed to be independent of the shape. Based on these shape options, the friction-factor prediction method appears to be restricted to just discrete disruptions; however, it was also recommended for wavy surfaces.

There were two recent publications (Arman and Rabas, 1992a, 1992b) that investigated the effect of different shapes, but only of the discrete type using a numerical prediction method. Arman and Rabats (1992a) showed that the thermal-hydraulic performance was not significantly changed with different disruption shapes with the same base dimension. The shapes considered were sine, are, semicircle, and trapezoid. The friction factors decreased when the shape changes in the following order: sine, trapezoid, semicircle, and arc. For the heat transfer, the trapezoid rather than the sine shape yielded the highest value. At a Reynolds number of 39,00$)$, the maximum variations of the friction-factor and heat-transfer values for the four shapes were about $16 \%$ and $7 \%$, respectively. These variations were less at a lower Reynolds number. Based on these numerical predictions, it appears that the thernal-hydraulic performance are not strongly shape dependent because of these small changes.

Arman and Rabas (1992b) also compared the thermal-hydralic performance for rectangular disruption shapes with widh-to-height ratios ranging from 0.5 to 2.0 . There was a small decrease of the friction factor with an increase in the width-to-height ratio and this difference increases with an increasing Reynolds number. The maximum deviation was about $9 \%$ at a Reynolds number of about 49,000 . The mean heat-transfer coefficient decreased slightly with in increase in the width-to-height ratio for low Prandt number fluids (air). However, the trend is more complex for higher Prandtl number fluids; it can either increase or decrease with an increalse in the wi lthto-height ratio depending on the magnitude of the Prandil number and the rib spacing. The maximum variation in the thermal pertomatr. $2 \mathrm{e}$, about $15 \%$, occurred for $\operatorname{Pr}=21.5$ and $p / c_{\max }=10.0$, the highest Prandtl number considered and for the closest spacing. This finding is consistent with previous findings in that the influence of the rib on the total performance increases as the Prandal number increalses (Rabals and Arman, 1992) and as the ribs are moved closer together. Becallse of the small deviations in both the friction factors and heat-transfer coefficients, the rib width does not appear to be a necessary correlating parameter for this particular discrete disruption shape.

\section{Wayy Shapes}

Only one publication, Kalinin et al. (1991), presented comparisons of experimental data obtained with different distuptions. shapes formed by a spirally indenting process. They meatsured the friction factors and heat-transfer coefficients for 16 different symmetric profiles using water as the test fluid. The shape of the profiles were characterized by a dimensionless parameter, $\langle e\rangle / c_{\max }$, defined as

$$
\frac{\leq e \geq}{\mathrm{e}_{\max }}=\frac{1}{\left(\mathrm{e}_{\max } p\right)} \int_{0}^{p} \mathrm{e}(\mathrm{x}) \mathrm{dx}
$$

The range of $<e>/ e_{\max }$ was considerable, varying from about 0.3 to 0.6 . For discrete disruptions, $\langle c\rangle / c_{\text {niax }}$ is almost alwalys less than about 0.1 . A surface profile of $\langle c\rangle / e_{\max }=0$. 6 is very differem from a discrete disruption. For an equivalent rectangular rib (c $=$ $e_{\max }$ ) with a height of $e$ and $p / e_{\max }=10$, the width-to-hicight is $\left(x_{\max }\right.$ with a spacing between the ribs of $4 \mathrm{c}_{\max }$. This profile begins to resemble internal grooves with a very wide rib.

Kalinin et al. (1991) discovered that there was a strong dependence of the hydraulic resistance on the shape or $\langle e\rangle / c_{\text {mix }}$ but the thermal performance was almost independent of the shipe. In particular, the friction factor was reduced by $25-4() \%$ when $\langle e\rangle / c_{\text {max }}$ was increased from 0.3 to 0.6 . Figure 2 taken from this work shows the type of variation that is obtained for the friction fictor with this shape change for $\mathrm{e}_{\max } / \mathrm{D}=\left(0.04\right.$ and $\mathrm{p} / \mathrm{c}_{\max }=10$.

Kalinin et al. (1901) claimed that the pressure drop is reduced with the wider shapes in a similar manner to the pressure-drop 
redection for flow through an orilice. For an orilice, the pressure drop is redued with a larger radius of curvature and with an increased length of the orilice heciase of the reduced flow contraction and resulting mean velocity. This analogy is not totally correct because of the interactions of adjacent distuptions and hecialuse the disruption heights of enhanced lubes are typically only an order of magnitude barger than the laminar houndary-layer thickness whereas an orifice extends lar into the turbulent core.

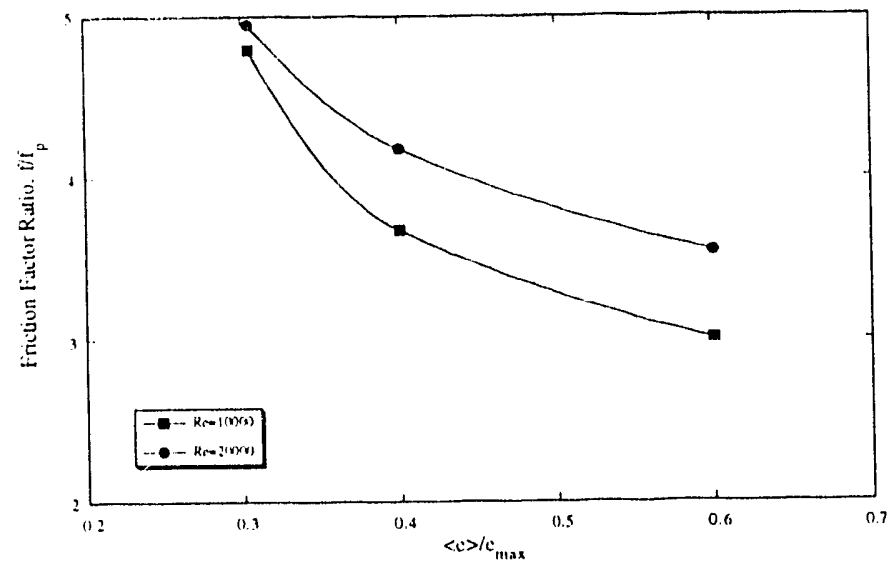

Figure 2 Variation of Friction Factor Ratio with Disruption Shape (Kalinin el al. 1991); $c_{\max } / D=0.04$ and $p / c_{\max }=10$

Kalinin et al. (194, ) also claimed that indented tubes should be designed with the maximum possible $<e>/ c_{\max }$ value. They argued that this configuration leads to the lowest pressure drop and yet does not ciatuse any measurable reduction in the thermal performance.

\section{Discrete and Wavy Sliapes}

Comparisons of triction-factor and heal-transfer data are now presented for different shapes - diserete and wavy. Figures 3 and 4 show the friction-factor and heat-transfer values, respectively, for a tube geometry with essentially the same maximum disruption height, $c_{\text {max }} / D=0 .(1)$ and $p / c_{\max }=20$ ). The test lluid was water (Pr in the 5 to 6 range). These geometry values and huid were picked because they permit comparisons of experimental data from six different sources: one for al discrete shane (Webhet al,. 1971) and five wavy or spirally indented shapes (Li et al., 1982; Gupta and Raja Rao, 1979; Mehta and Raja Rao, 1979; Withers, 1980). Table 1 lists the tube geometry for these six tuhes. A rectangular rib with a width-to-height ratio of about ().5 was selected by Webb et al. (1971).

\begin{tabular}{|c|c|c|c|c|}
\hline Source & $D(\mathrm{~mm})$ & $c_{\max }(1)$ & $p / e_{\max }$ & Shape \\
\hline Wehb el al. (1971) & 36.83 & 0.020 & 20. & rectangular, $w / c=0.52$ \\
\hline Liclall. (1082) & 17.81 & 0.024 & 17.52 & spirally indented \\
\hline Mehla and Ralja Rao (1979) & 15.90 & 0.02 & 19.84 & " \\
\hline (iupta and Raja Rac) (1979) & $25 .(x)$ & 0.02 & 20.00 & $"$ \\
\hline Willers (1981) & 20.4 .5 & 0.024 & $i 9.46$ & . \\
\hline Willers (1081) & 18.74 & 0.016 & 22.07 & " \\
\hline
\end{tabular}

Figure 3 shows that the measured liriction-lactor values for the tuhe with rectangular discrete distuptions are substantialy $y$ higher than the friction factor values obtained with the tubes made by the spirally indenting process. Also note that the friction factor for the transverse ribhed tube continuously increases and reaches an asymptotic value with increasing Reynolds number whereas the friction factors for the spirally indented abes continuously decreases with an increasing Reynolds number. There are some deviations in the friction-factor values for the four different spirally indented tubes because the maximum distuption height and pitch values and the measuring procedures used for each experiment were not identical. The frictionfactor values for the spirally indented tubes are ahout $60 \%$ less at a
Reynolds numbers of $10,(1)(0)$ and about a lactor of there less all at Reynolds number of $80,(\%)()$.

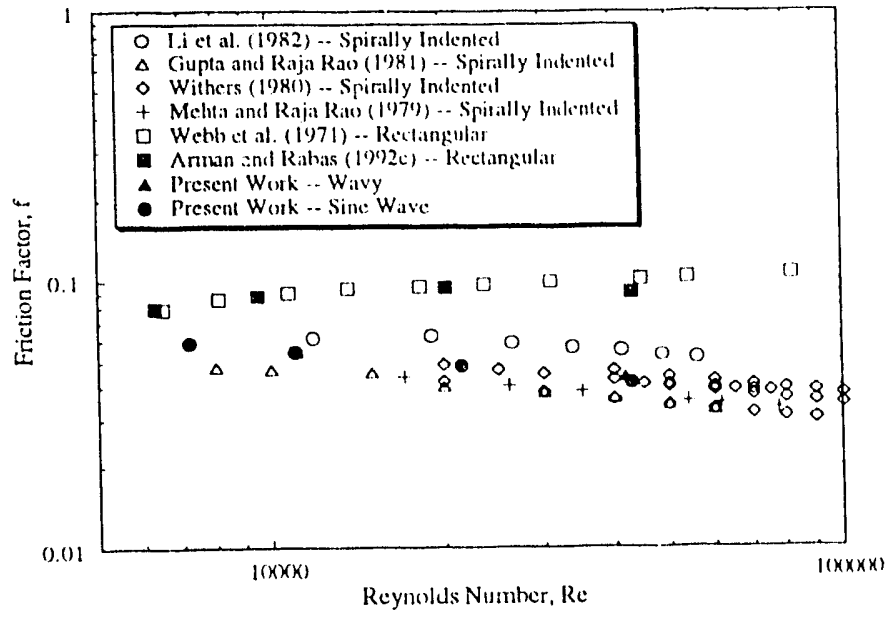

Figure 3 Variation of Friction Factors with Reynolds Number; $\mathrm{c}_{\max } / \mathrm{D} \approx 0.02$ and $p / \mathrm{c}_{\max }=10$

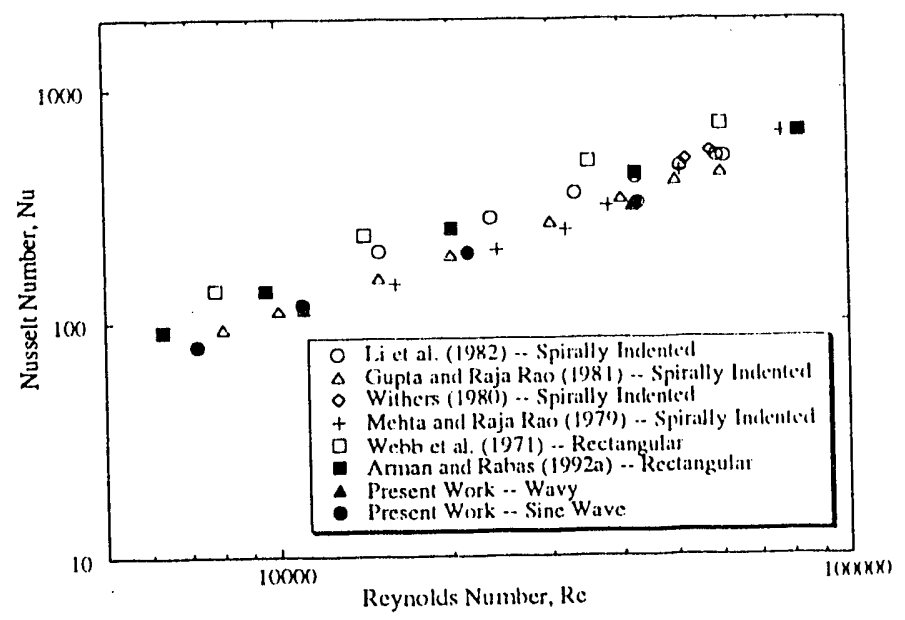

Figure 4 Variation of Mcan Nusselt Numbers with Reynolds Number

Also shown in Figure 3 are numerical predictions of the friclion factors for the discrete surface and for a wavy-sine and wavy-circular surface profiles. For the details of these numerical prediction methods, sce Arman and Rabas (1991, 1992a, and 1992c). The Iwo wavy surfaces that were selected for comparisons are shown in Figure 5. Note the good agreement between the experimental and numericial predictions for both the discrete and wavy surface types. Almost no difference existed between the predicted liriction factors lor the two profiles shown in Figure 3. The general pereeption is that the wavycircular profile is more representative of a spirally indented lube. This profile is generated with sectors of circles of different radii conliteting at a point with a common slope and is the same characterization used by Kalinin et al. (1991) for the indented tubes considered in some of their investigations. The Appendix discusses this particulat waty prolile in more detail.

Figure 4 compares the Nusscle numbers for the rectangular rit surface and the five spirally indented tubes. Nole that the experimental values obtained by Webhet al. (1971) are again higher than that obtained with the spirally indented tubes. Also nofe lle excellent agreement between these experimental and the numerically predicled heat-transfer coefficients, the latter heing described in detail by Rabas and Arman (1992) and Armann and Rahas (1992c). 
Figure 4 shows small reductions in the thermal-performance values with the spirally indented tubes from that obtained with the rectangular ribs. Also note that the magnitude of these reductions do not appear to be Reynolds number dependent. These differences are significint and can not be neglected; however, they are not accounted for with any of the published prediction methods. The reasons for the scalter of the Nusselt numbers values for these indented tubes are the slightly different tube geometries, Prandtl numbers, and experimental procedures and equipment.

Figure 4 also compares the numerically predicted heat-transfer coefficients with the data obtained with the spirally indented tubes. Again, both a wavy-sine and wavy-circular profiles shown in Figure 5 ;vere used. Note the reasonable agreement between the predictions and the experimental results and the wavy profiles used with the numerical model did not have any significant effect on the predicted vilues.

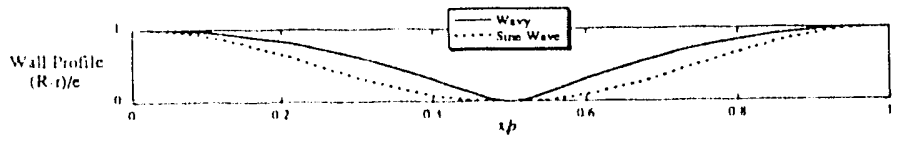

Figure 5 Wall Profiles of Tubes with $p / e_{\max }=20$

Based on these mean data, the following conclusions can now be made concerning the influence of the disruption shape for tubes with the separation and reattachment mechanism:

1) The disruption shape is not an important correlating parameter for discrete disruptions.

2) The friction fictor but not the heat transfer is influenced by the shape for wavy disruptions.

3) There are major differences between both the frictionfilctor and heat-transfer performance of transverse discrete and wavy disruptions with the same maximum disruption height and spacing.

The last portion of this paper will supply some of the fundamental reasons for the second and third conclusions listed above using local values of the wall shear stress, wall static pressure, and heat-transfer coefficients obtained with a numerical modeling program. The first conclusion listed above - the reasons why discrete disruption shapes do not influence the pressure drop and the thermal performance - was already addressed by Arman and Rabas $(1992 a, 1992 b)$. The second conclusion will be addressed first, that is when and why different wavy profiles have a significant effect on the friction factor but not the heat-transfer coefficient. This will be followed with an explanation for the major differences between both the friction-factor and tecat-transfer perfomance of discrete and wavy disruptions with the same spacing and maximum disription height.

\section{LOCAL PERFORMANCE COMPARISONS}

It is first shown with the predicted results that the wavy profile can influence the friction factor but not the thermal performance in the manner described by Kalinin et al. (1991). Finally, the reasons for the differences between the pressure-drop and heat-transfer performance of discrete and wavy disruptions are addressed. A nonothogonal, body-fitted, finite-volume numerical code is used for the present numerical simulations. Details of the numerical code is given in Arman and Rabas (1992c). The turbulence model used is the twolayer motel of Chen and Patel (1988).

\section{Influence of the Groove Radius}

A wavy surface profile must first be selected to represent that of a spirally indented tube. The selected profile for this analysis consists of two circular sectors that connect with a common slope. This representation of a wavy surfaces was previously used by Kalinin et al. (1991) and also was recommended for this andysis by thors (1993) of Wolverine Tube, Inc. Figure 6 shows three wavy prolites with groove radius to tuhe diameler ratios of $r_{1} / D=0.01$, (1).10, and 0.25 . The groove radius, $r_{1}$, is being the middle circular sector formed by the indenting tool. The equations used 10 gemeratle these profiles are presented in the Appendix. Comparisons of the mean and keal performance will now he presented lor these three groove radii.

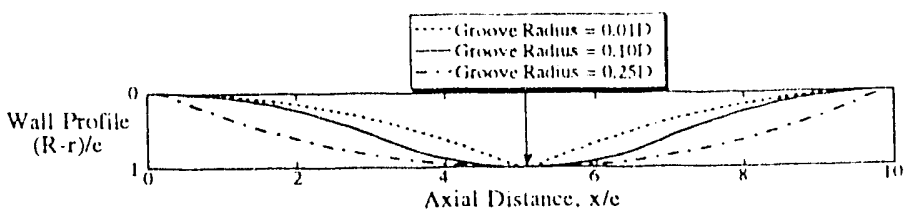

Figure 6 Wall Profiles of Tubes Considered

Consider first the mean performance. Figures 7 and 8 show the friction factors and heat-transfer coefficients, respectively, lor the same disruption height but different pitch values and the three groove radii. The disruption-tuhe diameter ratio, $c_{\text {max }} / D$, is $0 .(12$ and the theid is water $(\mathrm{Pr}=5.72)$. Note that suhstantial differences can exist wilh the friction factors but almost no differences exists hetween the heattransfer coefficients for each pitch value. These findings ale consistent with the experimental findings of Kalinin et al. (i)91). However, note that the differences decrease as the pitch increases. This finding can be explained by the fact that the variations of $<e>/ c_{\max }$ decrease with increasing $p / c_{\max }$ values as shown in the Appendix. These ligures elearly demonstrate that the energy efficiency can he significantly increased through the use of iarger groove radii, especially for operation in the higher Re range. For typical cooling-water applications, the Re values are always in this range or about 5()$, 0())$. The variations in the friction-factor values with the different groove radii decrealse as the disruption height increases; as a result, the maximum henelit are obtained with smaller distuptions.

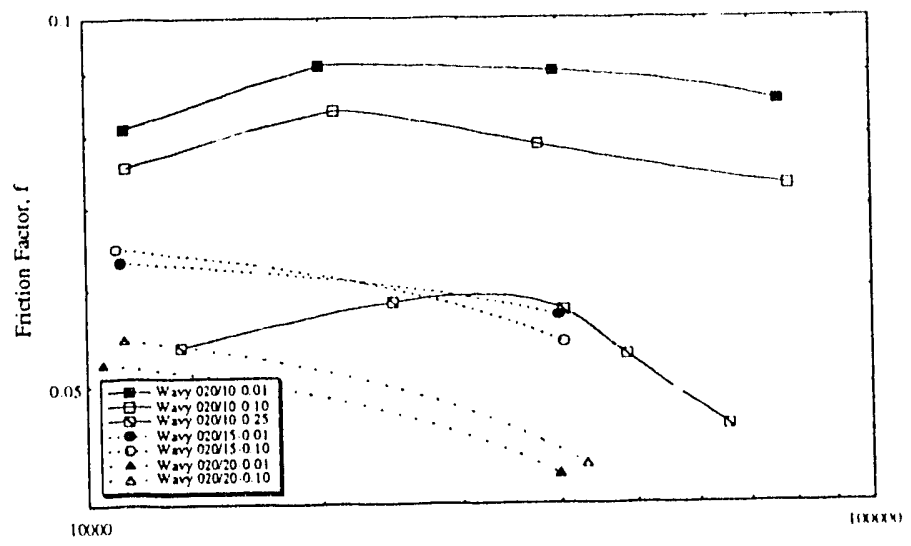

Reynolds Number, Re

Figure 7 Variation of Friction Factors with Reynolds Number; $c_{\text {max }} / D=(0.1) 2$

Consider next why there is a significant reduction of line liriction factor but no major change of the heat-transfer perlorm ance as the groove radius is increased. Comparisons of the locial wall pressure, shear stress, and heat-transfer coefficient distrihutions will he used to obtain these explanations. Conditions selected for the comparisoms. are as follows: the distuption height-to-diameler ration is (1).(12, the Reynolds and Prandtl numbers are about $4(1,0)(0)$ and 5.5 . respectively, and the pitch is $1\left(k_{\text {max }}\right.$. The lour groove radius-diameler ratios are used: $0.01,(0.10,0.17$ and 10.25 . First, the reasism for the friction-factor reduction is explaned.

The wall-pressure variations for lle four different groure ratlii are shown in Figure?. The entire wall pressure fiedd is alfecled by 
lie wave shape. The pressure drop around the wave crest increases sharply with a dectease in the groove radius. This pressure gradient is calsed by the lluid acceleration and the magnitude of this reduction is a measure of the form-drag loss. Note that the magnitude of this wallpressure drop is reduced with a larger groove radius or with a more contoured shape. There is a greater pressure recovery away from the crest for the lube with the larger groove radius.

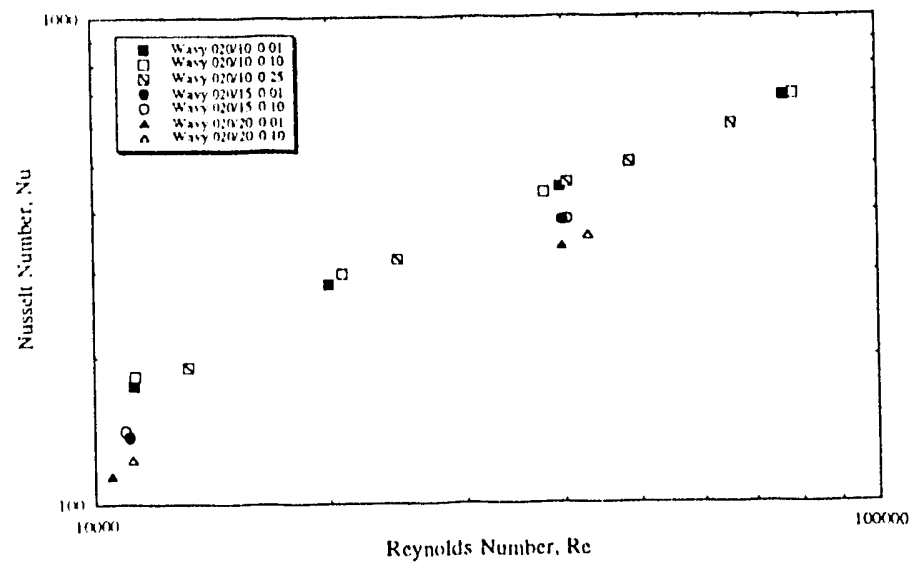

Figure 8 Variation of Mean Nusselt Numbers with Reynolds Number; $c_{\max } / \mathrm{D}=0 .(12$

More diflicult to explain is the reason why there is no major reduction in thermal performance with the larger groove radii. It will be shown that the heat-Iransfer on the upstream side of the disruption is increased to compensate for the reductions at the peak (crest) region and in the downstream recirculation region. Before comparing distributions of the local heat-transfer coeflicients for different groove radii, it is very helpful to analyze the influence of the groove radius on the wall shear stress.

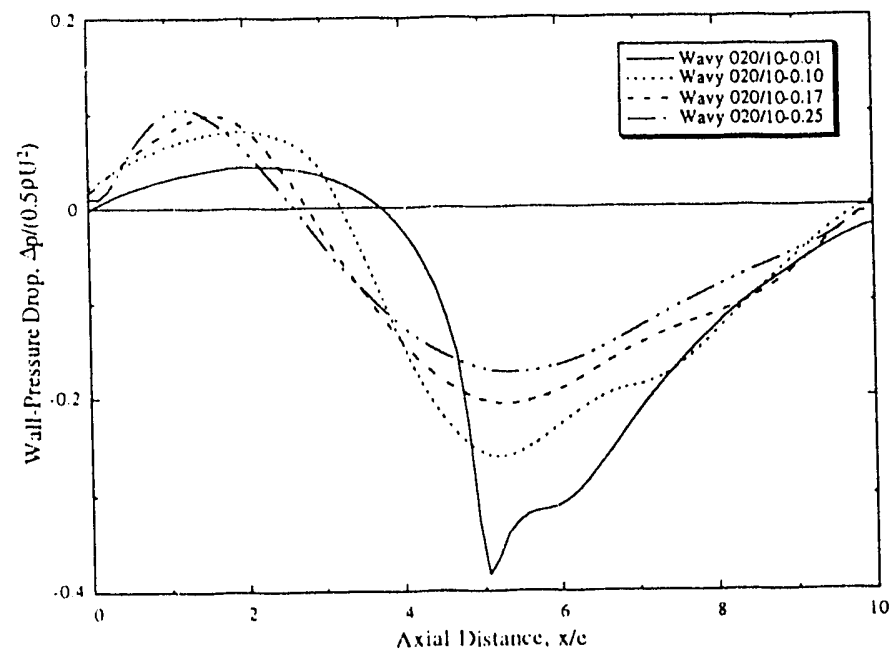

Figure) Axial Variation of Wall-Pressure Drops with $c_{\max } / D=0.02$ and $p / c_{\max }=10$

Figure 10) shows the normalized wall shear-stress distributions for lixe four groove radii. There is only one recirculation zone for all four of the shapes. The upstream zero value of the wall shear stress is the location of the realtachment point, at $x / c_{\max }$ equal to about 1 to 1.5. With an increase of the groove radius, this figure clearly shows that the wall shear stress becomes more uniform and the size of the recirculation region is reduced. The size of the recirculation regions are $5.68 c^{2}, 5.010_{\max }, 4.55 \mathrm{c}_{\max }$ and $3.710^{\circ}$ max for groove radii of

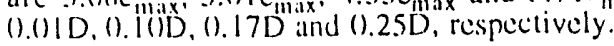

() particular interest is the change in the hehavior of the she:all stress at the front hall of the disruption. For this region of positive shear stress ( $x / e_{\text {max }}$ in about the 1 to 6 lange), the maximum moves upstream from the wave crest and its magnitude hecomes smaller with increasing groove radius. This also suggests that the locition and magnitude of maximum heat transier will move accordingly. The locations of ta inimum wall-shear stresses in the recirculation region will move furth: downstream with increasing gloove radius. This implics that the h alt transfer peaks within the recirculation region will also move further downstream. Also note that the lube with groove radius of ().25D has a very strong second wall-shear stress minimum just before the reatlachment point.

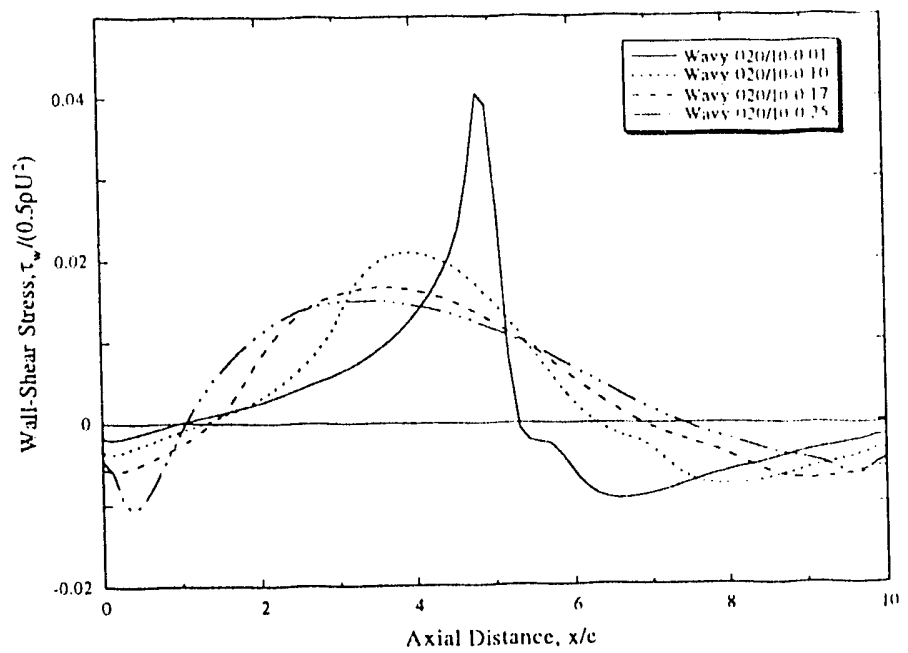

Figure 10 Axial Variation of Wall-Shcar Stresses with comix $/ D=0.12$ and $p / c_{\max }=10$

Figure 11 shows that distributions of the local heal-transter coefficient for the same lour groove radii. First consider the recirculation region. The high heat-transfer enhancement in the recirculation region is the result of kinctic energy generaled in the shear layer due to the separation process and convected to the surliace near the reattachment point (Mori and Daikoku, 1972). Numericill predictions (Rabas and Arman, 1992 and Arman and Rabas., 1992c) suggest that the location of this maximum heal transfer is locilled between the point of maximum negative wall sliear stress and the realtachment point. The location of maximum heal transler will move further downstream with increasing groove radius and is lociated hetween the shear stress minimum and the reallachmeme point, closer to the shear stress minimum. However, the movement of the heilltransfer peak is a function of Reynolds and Prandil numbers (Armim and Rabas, 1992c). Figure 11 shows that the tubes with a larger groove radius will not achieve as high a contrihution to the lotal healt transfer from the recirculation region. However, the size of the recirculation region is reduced with larger groove radius so the implact of this effect is minimized.

Now consider the wave crest region. Figure 11 shows that the local Nusselt number distributions show a maximum lor each prolile and that the location moves further upstream fiom the wave crest will an increasing groove radius. This is similar to the maximum of the wall-shear stress. The location of the heat-transfier maximum corresponds exactly with the shear-stress maximum for the luhe will the smallest groove radius ((O.)ID); however, the locition moves the smallest groove radius (O). from the locition of the she alr -stress maximum with increasing gronve radius. For the tuhe will groove radius of $0.25 D$, the location of maximum is moved about on the reattachment point and the second shear-stess minimum. The reattachment point and he seen the recirculation \%one and the core region will impact on the second wave crest. Thus this increased curbulence level causes the high heal-thansfer performance. Will an increase in the groove radius, Figute II clearly shows that dle heat- 

Cranstior reduction in the smaller recirculation region is compensated by the increasing contribution from the wave crest region.

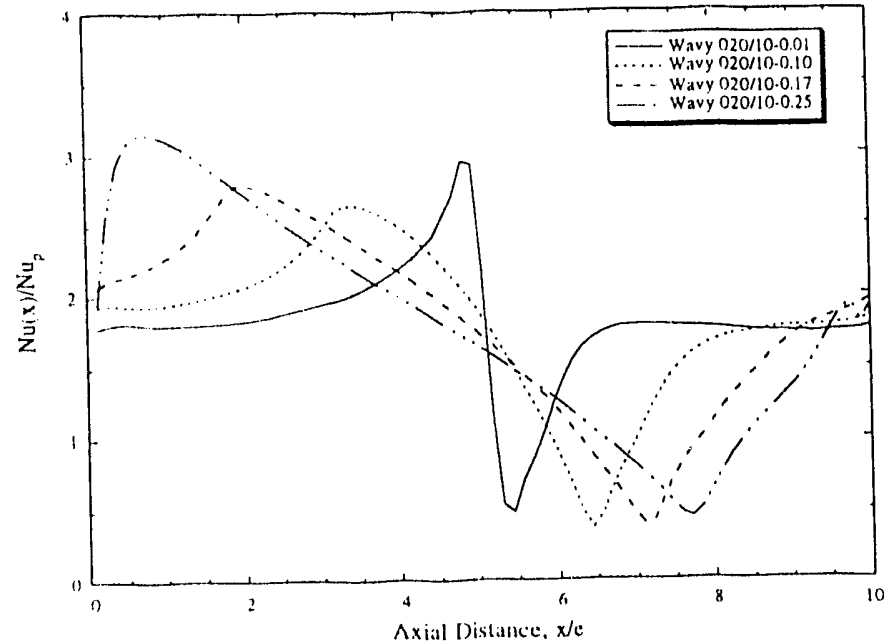

Figure 11 Axial Variation of Nussell Numbers with $\mathrm{c}_{\max } / \mathrm{D}=0.02$ and $p / c_{\max }=10$

\section{IVavy and Discrete Shapes}

Comparisons of the local performance characteristics of a wavy and discrete disruptions are now presented for enhanced tubes with and $D=0 .(1), p / c=10$, and Reynolds and Prandll numbers of max $40,(K)$ and 572 , respectively. A discrete disruption can be considered as a limiting case of a wavy surface with a very small grovere radius. As a lesult, much of the previous discussion on wavy surface's is applicable for these comparison.

Figure 12 compares the wall shear stress for a trapezoidal rib (hase width equals $2 e_{\max }$ and a base angle of 68.2 degrees) and a wavy surfiace with a groove radius of $0.01 \mathrm{D}$. There are three major features of the ribhed lute worthy of noting:

1) a negative and a very large positive peak near the front and top windward faces, respectively

2) larger downstream recirculation region

3) al small upstream recirculation region

When the shear stress is negative, which a characteristic of reciculation how regions, the dominant flow type controlling the heat-transfier enhaneement is separating and realtaching rather than boundary-layer. Figure 12 shows that the controlling enhancement mechanism for the ribbed tube is separation and reattachment because the negative shear stress exists for most of the axial distance between two adjacent distuptions.

These features are in sharp contrast to that shear-stress profile obtained with the wavy surface. For this case, a typical houndarylayer type llow exists for the majority of the axial distance similar to that in a smooth tube. However, the magnitude is greater than the smooth-tube value in the front half of the tube because of the mean now acceleration for most of the front half of the disruption.

The friction factor variation with the Reynolds number in turbulent llow has two limiting charackeristics:

1) independent of the Reynolds number when the form drat is controlling - separating and reattaching flows rickds
2) a negative slope (slope of ahout (1.25) when the frictional contribution is controlling - houndary-layel now ficlds

For discrete disruption shapes, the friction lactor is independent of the Reynolds number for most of the range as is clearly shown in Figure 3. However, the decrease in the friction factor with Reynolds number for the spirally indented tuhes suggests the houndary-layer llow is more dominant than separating and reattaching flows. The local shear stress variations shown in Figure 12 demonstrate that this is indeced the case - scparating and reattaching dominales with discrele disruptions and boundary-layer flow characteristics dominatc with wavy disruption profiles.

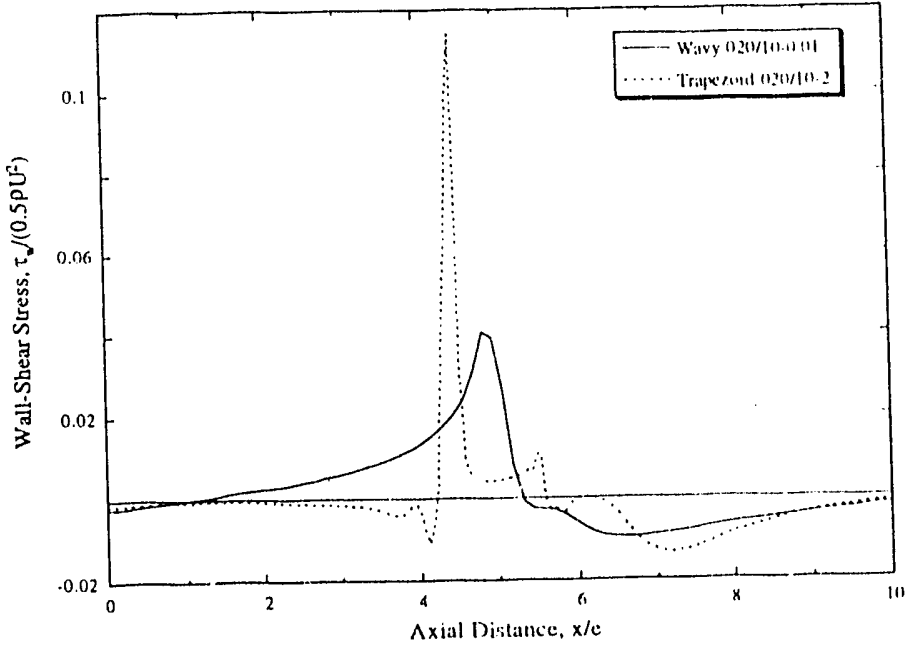

Figure 12 Axial Variation of Wall-Shear Stresses for Trape\%oidal Rih and Wavy Tubes

Figure 13 shows that there also are dramatic differences in the distributions of the local heat-transfer coeflicients. With the discrete disruption, most of the enhancement occurs in the vicinity of the disruption and in the reattachment region and almost no enhancement is obtained upstream of the disruption. The superior locial thermal performance of wavy protiles in this region is the explanation why the mean thermal performance (the integrated average for the entire axial distance) is comparable to that obtained with discrete distuptions.

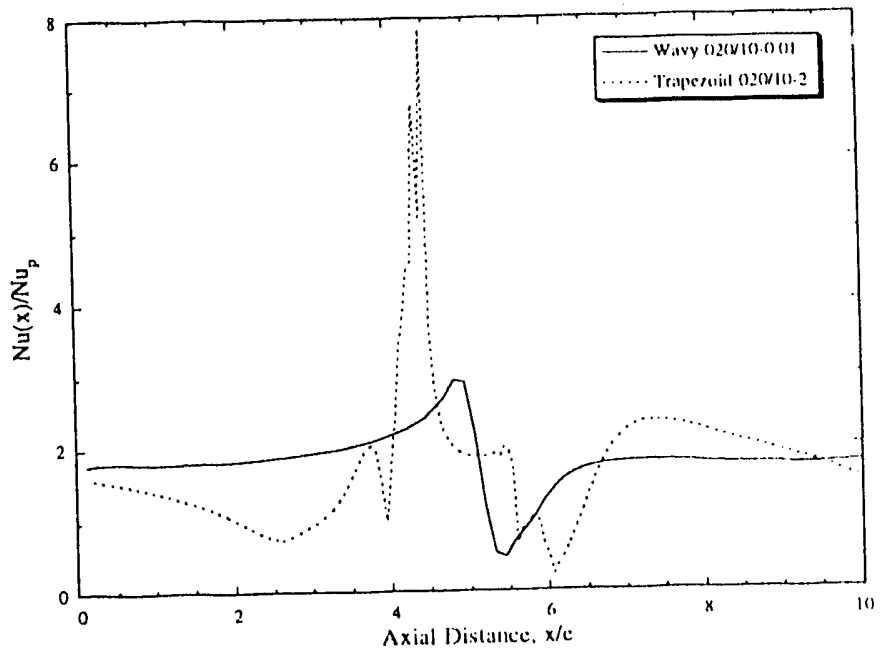

Figure 13 Axial Variation of Nusselt Numbers lior Thapeznidal Rit and Wavy Tuhes 


\section{CONCLUSIONS}

The most important conclusion of this investigation is that the uroove radii currently being used hy manufacturers of spirally indented luhes are too small. A larger groove radius would indented tuhes are the pressure drop but only slightly reduce the leatl-tansfer performance. As a result, tuhes made with a larger groove radius will he more energy efficient. This conclusion was previous!y reached hy Kalinin et al. (1991) with experimental data and is further supported with the results from this investigation.

Some other conclusions regarding the influence of the disruption shape oblained hy comparisons of data and numerical results are as follows:

1) The shape is not a important correlating parameter for discrete disruptions - disruptions with base widths that are less than about twico the maximum height.

2) The shape is a necessary correlating parameter of the friction factor hut not the heal-transfer performance for wavy distuptions.

3) There are majo differences between hoth the frictionfactor and the heat-transfer performance values ohtained with discrete and wavy disruptions with the same maximum height and pitch. The differences in the thermal performance are not large about 20 to $30 \%$, hut certainly can not be neglected.

\section{REFERENCES}

Anisimova, O.S., et al., 1982, "A Comparative Investigation of the Resistance to Corrosion of Smooth and Profiled Brass Tuhes," Thermal Engine'ering. Vol. 29, np. 452-456.

Arman B., and T.J. Rahas, 1992a, "Disruption Shape Effects on the Performance of Enhanced Tubes with the Separation and Realtachinent Mechanism," Enhanced Heat Transfer, ASME HTDVol. 2(1), 67-76.

Arman B. and T.J. Rabas, 1992h," The Influence of the Rib Width on the Performance of Tuhes with the Scparation and Reallachment Enhancement Mechanism," Fundcumentals of Forced Comvection Heal Transfer, ASME HTD-Vol. 210, pp. 159-166.

Arman B., and T. J. Rabas, 1992c, "Influence of Prandtl Number and Effects of Disruption Shape on the Performance of Enhanced Tuhes with the Separation and Reatlachment Mechanism," Argonne National Laboralory, ANLJESD-16.

Arman B., and T.J. Rabas, 1991, "Prediction of the Pressure Drop in Transverse, Repeated-Rib Tubes with Numerical Modeling," Fouling and Enhancement Interactions, ASME HTD-Vol. 164, p. 93-99.

Chen, H.C., and V.C. Patcl, 1988, "Near-Wall Turbulence Models for Complex Flows Including Separation," AIAA J., Vol. 26, pp. $641-648$

Hijikata, K., and Y. Mori, 1987, "Fundamental Study of Heat Transfer Augmentation of Tuhe Inside Surface by Cascade Smooth Surlace-Turbulence Promoters," Wärme-und Stoffiabertragung. Vol. 21, pp. 115-124

Gupla, R.H., and M. Raja Rao, 1979, "Heat Transfer and Friclional Characteristics of Spirally Enhanced Tuhes for Horizontal Condensers," Adrancess in Enhanced Heat Transfer, ASME, San-Dicgo, pp. 10.3-114
Houle, J.F., and W.T. Buhrig, 1973, "Performance of Freeport, Texas, VTE/MSF Plant," Ath International Sympositum on Fre'sh Water from the Sea, Vol. 1. pp. 31.3-31k

Inoue, S., T. Tsuruta, and S. Funshashi, 1975, "Multiple Effict VTE Desalination Plant Experiences in Operation and Performance S(K) Ton/Daty Plant at Innoshima Shipyard," Heat Transfer Japanese Research, Vol. 4, pp. 1-19)

Kalinin, E.K., G.A. Drcister, N.V. Paramonov, A.S Myakochin, A.I Tikhonov, S.G. Zakirov, E.S. Levin, L.S Yanovsky, 1991, "Comprehensive Study of Heal Transfer Enhancement in Tubular Heat Exchangers," Experimental The'rmal and Fluid Science, Vol. 4, pp. 656-666.

Katsman, D., and Y. Kishinevsky, 1983, "Spiral, High Strength, Corrosion-Resistance Tube Application in PWR Power Plant Condensers," ASME Paper 8.3-JPGC-Pwr-17.

Li, H.M., K.S. Ye, Y.K. Tan, and S.J. Den, 1982, "Investigation of Tube-Side Flow Visualization, Friction Factors and Heat Transfor Characteristics of Helical-Ridging Tubes," Proceeding of the Seventh International Heat Transfer Conference, Hemisphere Publishing Co., Washington. D.C., Vol. 3, pp. 75-80.

Mehta, M.M., and M. Raja Rao, 1979, "Heat Transfer and Frictional Characteristics of Spirally Enhanced Tuhes for Horizontal Condensers," Advances in Enhanced Heat Transfer, San Diego, pp. 11-22.

Mori, Y., and T. Daikoku, 1972, "Elfect of 2-Dimensional Roughness on Forced Convective Transfer," Bulletin of the JSME, Vol. 15, pp. 1581-159).

Nikolacv, G.V., V.V. Nazarov, G V. Grigorev, and Y.N. Bogolyuhor, ig82, "Comparative Stucies of a 260$) \mathrm{KT}$ SS-2 Condenser with Smooth and Rolled Tubes," Energomashinostroenie, Vol. 1. pp. 15-16.

Nunner, W., 1956, "Heat Transfer and Pressure Drop in Rough Tubes," A.E.R.E. Lib/Trans. 786 (1958).

Rabas, T.J., 1989, "Sclection of the Energy-Efficient Enhancement Geometry for Single-Phase Turbulent Flow Inside Tubes," Heat Transfer Equipment Fundamentals, De'sign, Applications and Operating Problem.s. ASME HTD-Vol. 108 , pp. 193-204

Rabas, T.J., and B. Arman, 1992, "The Influence of the Prandt Number of the Thermal Performance of Tuhes with the Separation and Reatlachment Mechanism," Enhanced Heat Transfer, ASME HTDVol. 2()2, 77-88

Rabas, T.J., R. Merring, R. Schalefer, R. Lopez-Gomez, and P. Thors, 1990) "Heat-Rate Improvements Ohtianed with the Use of Enhanced Tuhes in Surface Condensers," EPRI Condenser Technology Conference, Boston, MA.

Ravigururajan, T.S., and A.E. Bergles, 1985. "General Correlations for Pressure Drop and Heat Transfer for Single-Phase Turbulent Flow in Internally Ribhed Tubes," Augmentation of Heat Transfer in Energy System., ASME HTD-Vol. 52. pp. 9-2().

Rowe, M.. 1983, "Power Plant Condensers - Recent CEGB Experience," Condensers: Theory and Practice, The Institution of Chemical Engineers, Symposium Scries No. 75, pp. 11.3-1.34.

Thors P.. 1993, Personal Communication. 
Wcht. R.L., E.R.G. Eckert, and R.L. Goldstein, 1971, "Heat Trithsfer and Friction in Tubes with Repeated-Rih Roughness," Internarional Journal of Heat and Mass Transfer, Vol. 14, pp. $6(1) 1-6(1) 7$.

Withers, J.G., 1980, Tube-Side Heal Transfer and Pressure Drop for lubes Having Helical Internal Ridging with Turbulentransitional Flow of Single-Phase Fluid, Part 1, SingleHelix Ridging," Heat Transfer Engineering. Vol. 2, pp. 48-58.

\section{APPENDIX}

The purpose of this Appendix is to present the geometry variation expressions selected to represent spirally-indented or wavy tube profiles. These surfaces censist of two circular sectors that connect with a common slope. Let $\beta$ be the contact angle of the two circles, $r_{1}$ the external groove radius, and $r_{2}$ the radius of the other circular sector. It is easy to show the following:

$$
\begin{aligned}
& p=2\left[r_{1} \sin (\beta)+r_{2} \sin (\beta)\right] \\
& c_{\max }=r_{1}[1-\cos (\beta)]+r_{2}[1-\cos (\beta)] \\
& \frac{p}{c_{\max }}=\frac{2 \sin (\beta)}{[1-\cos (\beta)]}
\end{aligned}
$$

The three independent variables are the disruption pitch $(p)$ maximum height $\left(c_{\max }\right)$, and the groove radius $\left(r_{1}\right)$. The tangen contact angle, $\beta$, is calculated implicitly with Equation $A .3$ and $r_{2}$ is then calculated with either Equations A1 or A2. Knowing these quantities, $e(x)$ can be calculated for any value of $x$ in a straightforward manner and will not be discussed.
The ratio $<e>/ e_{\text {max }}$ defined in Eyuation 1 can he dekermined for different values of $e_{\text {max }} / D, p / c_{\text {max }}$ and $r_{1} / D$ for this wavy prolile type. Table Al shows the variations of $<c>c_{\text {max }}$ with typical $c_{\max } / \mathrm{D}, \mathrm{p} / \mathrm{c}_{\max }$ and $r_{1} / D$ values. The important point is that small $e_{\text {max }} / D$ and $p / e_{\text {max }}$

\begin{tabular}{|c|c|c|c|}
\hline Table A I & $\left\langle e>/ c_{\max }\right.$ Varii & $\mathrm{hc}_{\max }$ & $\max$ and $r_{1}$ \\
\hline $\mathrm{c}_{\max } / \mathrm{D}$ & $p / c_{\max }$ & $r_{1} / \mathrm{D}$ & $<c>/ c_{\operatorname{mix}}$ \\
\hline \multirow[t]{9}{*}{0.01} & \multirow[t]{3}{*}{10.0} & 0.01 & 0.355 \\
\hline & & 0.10 & $(0.59 .3$ \\
\hline & & 0.25 & 0.829 \\
\hline & \multirow[t]{3}{*}{20.0} & 0.01 & 0.3 .39 \\
\hline & & (0.10) & 0.399 \\
\hline & & 0.25 & 0.498 \\
\hline & \multirow[t]{3}{*}{$4(0.0$} & 0.01 & 0. .335 \\
\hline & & 0.10 & (). .350 \\
\hline & & 0.25 & (0).375 \\
\hline \multirow[t]{9}{*}{0.02} & \multirow[t]{3}{*}{10.0} & 0.01 & 0.341 \\
\hline & & 0.10 & $(0.460)$ \\
\hline & & 0.25 & $(0.659$ \\
\hline & \multirow[t]{3}{*}{20.0} & ().01 & (). .335 \\
\hline & & 0.10 & (). .365 \\
\hline & & (). 25 & 0.415 \\
\hline & \multirow[t]{3}{*}{4() .0} & 0.01 & (). .334 \\
\hline & & 0.10 & (). .341 \\
\hline & & 0.25 & (). .358 \\
\hline \multirow[t]{9}{*}{0.04} & \multirow[t]{2}{*}{10.0} & 0.01 & 0.335 \\
\hline & & 0.10 & ()..394 \\
\hline & & 0.25 & (0.493 \\
\hline & \multirow{3}{*}{20.0} & 0.01 & 0.3 .34 \\
\hline & & 0.10 & ()..349 \\
\hline & & (). 25 & (). .374 \\
\hline & \multirow{3}{*}{40.0} & 0.01 & 0.334 \\
\hline & & 0.10 & 0.3 .37 \\
\hline & & 0.25 & (0.343 \\
\hline
\end{tabular}
values and/or large changes in $r_{1} / D$ are needed to obtain significant variations in the values of $<e>/ c_{\max }$.

\section{DISCLAIMER}

This report was prepared as an account of work sponsored by an agency of the United States Government. Neither the United States Government nor any agency thereof, nor any of their employees, makes any warranty, express or implied, or assumes any legal liability or responsibility for the accuracy, completeness, or usefulness of any information, apparatus, product, or process disclosed, or represents that its use would not infringe privately owned rights. Reference herein to any specific commercial product, process, or service by trade name, trademark, manufacturer, or otherwise does not necessarily constitute or imply its endorsement, recommendation, or favoring by the United States Government or any agency thereof. The views and opinions of authors expressed herein do not necessarily state or reflect those of the United States Government or any agency thereof. 

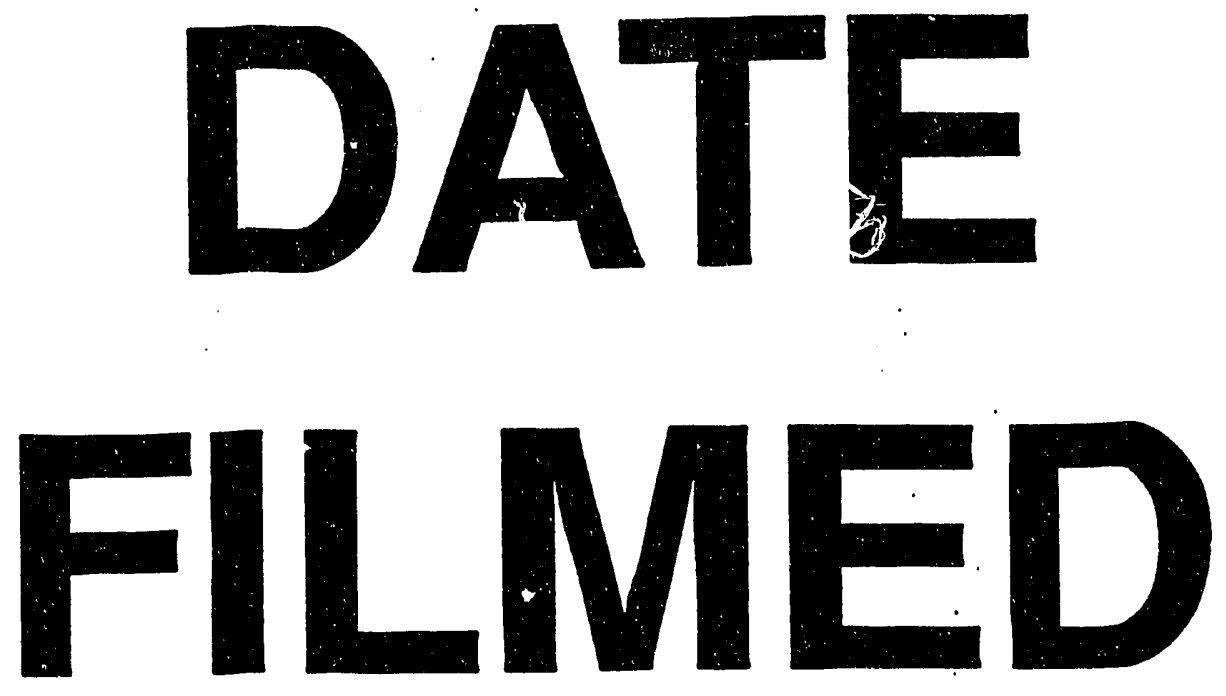

II

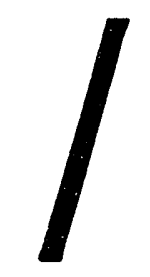

91

93
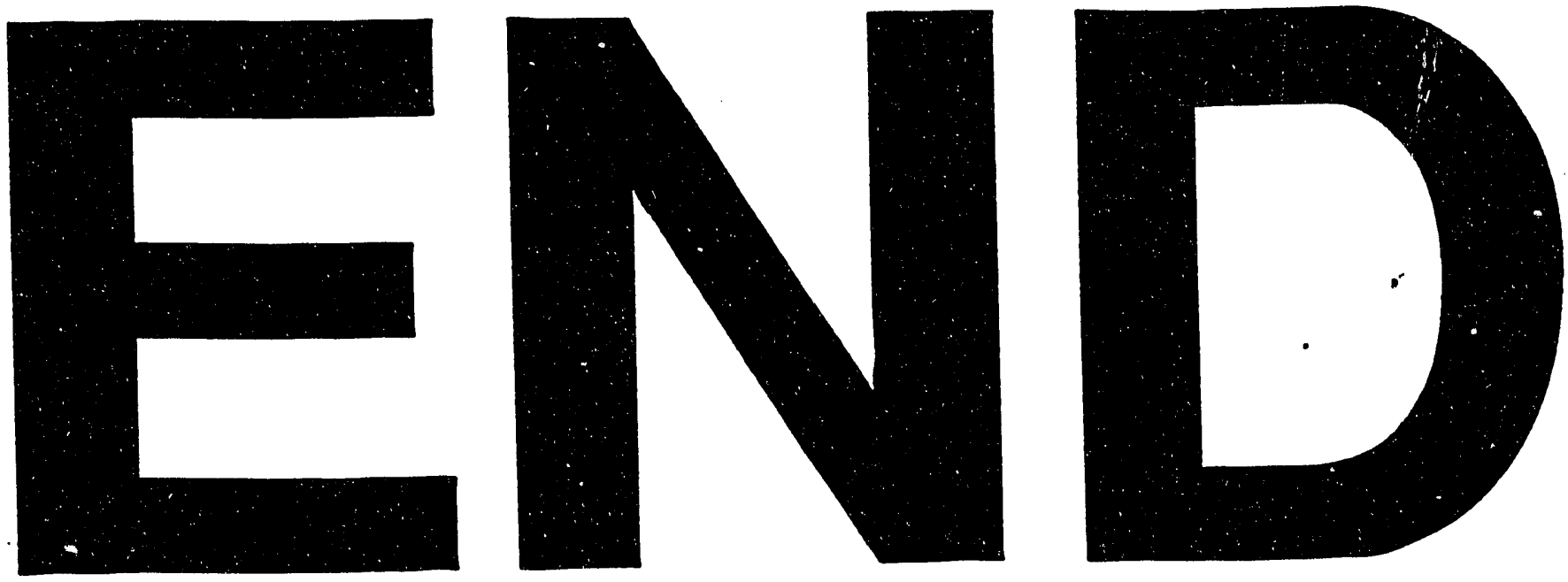
